\title{
HUBUNGAN PERKEMBANGAN EMOSIONAL TERHADAP PERILAKU MENYIMPANG PADA USIA REMAJA SEKOLAH MENENGAH PERTAMA BUKIT RAYA PEKANBARU TAHUN 2015
}

\author{
Yeni Devita, Pratiwi Gasril, Tengku Muhammad Hafis
}

\author{
Staf Dosen Sekolah Timggi Ilmu Kesehatan Payung Negri Pekanbaru \\ Staf dosen DIII Keperawatan Universitas Muhammadiyah Riau \\ Alumni DIII Keperawatan Dharma Husada Pekanbaru
}

Email: vitandesta@ymail.com

\begin{abstract}
ABSTRAK
Masa remaja awal merupakan masa transisi yang mempengaruhi perkembangan emosional dan kejiwaan.Masa transisi juga dapat menimbulkan masa krisis, yang ditandai dengan kecenderungan munculnya perilaku menyimpang. Data survei yang dilakukan di 33 Provinsi pada pertengahan tahun 2010 yang dilakukan oleh Direktur Remaja dan Perlindungan Hak-hak Reproduksi BKKBN melaporkan bahwa 63\% remaja di Indonesia usia Sekolah Menengah Pertama dan Sekolah Menengah Atas sudah melakukan hubungan seksual diluar nikah dan $21 \%$ diantaranya melakukan aborsi. Data provinsi riau khususnya Pekanbaru terdapat Sebanyak 3.323 anak yang berumur kurang dari 16 tahun menjadi warga binaan di Lembaga Pemasyarakatan kelas IIA pekanbaru terlibat sejumlah tindakan pidana. Tujuan penelitian ini adalah untuk mengetahui perkembangan emosional terhadap perilaku menyimpang pada usia remaja Sekolah Menengah Pertama Bukit Raya Pekanbaru tahun 2015.

Jenis penelitian ini adalah penelitian kuantitatif dengan desain penelitian analitik dengan cara penelitian cross sectional dengan menggunakan teknik perposive sampling. Penelitian ini dilakukan di Sekolah Menengah Pertama Bukit Raya Pekanbaru yang terletak di Jl. Sialang Bungkuk, pada bulan Mei 2015. Populasi dalam penelitian ini adalah 368 orang dengan sampel sebanyak 79 orang siswa/i, dengan bersumber pada data primer dan data sekunder.

Hasil penelitian ini adalah sebanyak 42responden(53,16\%) memiliki perkembangan emosional normal, 27 responden $(34,17 \%)$ borderline, dan sebanyak 10 responden $(12,65 \%)$ memiliki perkembangan emosional abnormal. Sedangkan sebanyak 63 responden $(79,74 \%)$ tidak melakukan perilaku menyimpang dan 16 responden (20,25\%) melakukan perilaku menyimpang. Hasil dari Chi square 0,08 p value $>0,05$ maka Ho ditolak berarti tidak terdapat hubungan antara perkembangan emosional terhadap perilaku menyimpang pada usia remaja SMP bukit raya pekanbaru.

Kesimpulan dari penelitian ini adalah perkembangan emosional siswa/i tergolong normal dengan tingkat penyimpangan perilaku yang rendah. Diharapkan guru dan orang tua mengontrol dan membimbing siswa/i agar tidak terlibat atau melakukan perilaku menyimpang.
\end{abstract}

Kata Kunci: Remaja, Perkembangan Emosional, Perilaku Menyimpang

\section{PENDAHULUAN}

Perkembangan adalah perubahan psikologis sebagai hasil dari proses pematangan fungsi psikis dan fisik pada diri anak, yang ditunjang oleh faktor lingkungan dan proses belajar dalam peredaran waktu tertentu menuju kedewasaan yang mempengaruhi perkembangan emosional dan kejiwaan. Perkembangan emosional dan kejiwaan juga mengikuti pola-pola yang dapat dikenali, perkembangan ini juga berjalan maju bersamaan dengan pertumbuhan dan kematangan biologis (Suherman, 2007).

Reed Larson dan Maryse Richards (1994) menemukan remaja melaporkan emosi yang lebih ekstrem dan lebih berubah-ubah dibandingkan dengan orang tua mereka (Santrock, 2007).
Masa remaja awal merupakan masa transisi, dimana usianya berkisar antara 13 sampai 16 atau 17 tahun dan akhir masa remaja bermula dari 16 atau 17 tahun sampai 18 tahun. Pada masa transisi tersebut kemungkinan dapat menimbulkan masa krisis, yang ditandai dengan kecenderungan munculnya perilaku menyimpang. Pada kondisi tertentu perilaku menyimpang tersebut akan menjadi perilaku yang mengganggu(Tarwoto, $\mathrm{dkk}, 2010)$.

Remaja cenderung suka mencoba hal baru, dalam artian diusia ini remaja masih mencari jati dirinya. Remaja lebih suka bergaul dengan teman sebaya atau membentuk kelompok dari pada menyendiri. Dari sinilah perilaku menyimpang ini dapat timbul. Bagi remaja yang tidak dapat 
mengontrol dirinya dan tidak bisa menyaring setiap kebudayaan negatif dari luar yang masuk akan menimbulkan penyimpangan pada remaja (Rasmun, 2009).

Data survei yang dilakukan di 33 Provinsi pada pertengahan tahun 2010 yang dilakukan oleh Direktur Remaja dan Perlindungan Hak-hak Reproduksi BKKBN melaporkan bahwa 63\% remaja di Indonesia usia Sekolah Menengah Pertama dan Sekolah Menengah Atas sudah melakukan hubungan seksual diluar nikah dan $21 \%$ diantaranya melakukan aborsi (Suara Karya, 2010). Data provinsi riau khususnya Pekanbaru terdapat Sebanyak 3.323 anak yang berumur kurang dari 16 tahun menjadi warga binaan di Lembaga Pemasyarakatan kelas IIA pekanbaru terlibat sejumlah tindakan pidana (Lapas Anak, 2014).

Dari survey awal yang peneliti lakukan di Sekolah Menengah Pertama Bukit Raya Pekanbaru, peneliti mendapatkan data bahwa pada tahun 2012 terdapat sebanyak 5,97\% siswa yang melakukan perilaku menyimpang, pada tahun 2013 terdapat $5,97 \%$ siswa yang melakukan perilaku menyimpang, dan pada tahun 2014 sebanyak 3,26\% siswa yang melakukan perilaku menyimpang. Dapat disimpulkan bahwa pada tahun 2012 dan 2013 siswa yang melakukan perilaku menyimpang mengalami persentase tetap $5,97 \%$, sedangkan pada tahun 2014 mengalami penurunan sebesar 2,71\% (Profil SMP Bukit Raya, 2014).

Selain itu, peneliti juga mewawancarai kepala sekolah SMP Bukit Raya bahwa terdapat beberapa siswa Sekolah Menengah Pertama Bukit Raya Pekanbaru melakukan tindakan seperti merokok di masyarakat dengan menggunakan seragam sekolah, pergi sekolah terlambat, kebut - kebutan di jalan raya, dan bolos pada jam pelajaran. Tidak hanya itu saja, terdapat siswa/i yang dikeluarkan dari sekolah dikarenakan melakukan seks bebas.

\section{METODOLOGI PENELITIAN}

Jenis penelitian ini adalah penelitian kuantitatif dengan rancangan deskriptif analitik. Desain yang digunakan adalah desain cross sectional. Penelitian ini dilakukan pada tanggal
12 Mei s.d 15 Mei 2015.Sampel yang digunakan dalam penelitian ini berjumlah 79 orangdenganteknik Purposive Sampling

\section{HASIL DAN PEMBAHASAN}

Penelitian ini dilakukan Sekolah Menengah Pertama (SMP) Bukit Raya Pekanbaru dengan hasil penelitian sebagai berikut:

\section{Tabel 1}

Distribusi Perkembangan Emosional Remaja Sekolah Menengah Pertama (SMP) Bukit Raya Pekanbaru Tahun 2015

\begin{tabular}{|c|c|c|c|}
\hline No & $\begin{array}{c}\text { Perkembangan } \\
\text { Emosional }\end{array}$ & (f) & (\%) \\
\hline 1 & Normal & 42 & 53,16 \\
\hline 2 & Borderline & 27 & 34,17 \\
\hline 3 & Abnormal & 10 & 12,65 \\
\hline \multicolumn{2}{|c|}{ Total } & 79 & 100 \\
\hline
\end{tabular}

Hasil analisis didapatkan mayoritas responden memiliki perkembangan emosional yang normal dengan frekuensi sebanyak 42 orang dengan persentase sebanyak $53,16 \%$.

\section{Tabel 2}

Distribusi Perilaku Menyimpang Remaja Sekolah Menengah Pertama (SMP) Bukit Raya Pekanbaru Tahun 2015

\begin{tabular}{|c|c|c|c|}
\hline No & $\begin{array}{c}\text { Perilaku } \\
\text { Menyimpang }\end{array}$ & (f) & (\%) \\
\hline 1 & Ada & 16 & 20,25 \\
\hline 2 & Tidak Ada & 63 & 79,74 \\
\hline & Total & 79 & 100 \\
\hline
\end{tabular}

Hasil analisis menunjukkan bahwa dari 79 orang responden di Sekolah Menengah Pertama Bukit Raya mayoritas tidak melakukan perilaku menyimpang dengan frekuensi 63 orang dengan persentase $79,74 \%$.

\section{Tabel 3}

Hubungan Perkembangan Emosional Terhadap Perilaku Menyimpang Pada Remaja Di Smp Bukit Raya Pekanbaru Tahun 2015

\begin{tabular}{|c|c|c|c|c|c|c|c|}
\hline \multirow{3}{*}{$\begin{array}{l}\text { Perkem } \\
\text { bangan } \\
\text { Emosional }\end{array}$} & \multicolumn{4}{|c|}{ Perilaku Menyimpang } & \multirow{2}{*}{\multicolumn{2}{|c|}{ Total }} & \multirow{3}{*}{$\begin{array}{l}\mathbf{P} \\
\text { Value }\end{array}$} \\
\hline & \multicolumn{2}{|c|}{ Ada } & \multicolumn{2}{|c|}{$\begin{array}{l}\text { Tidak } \\
\text { Ada }\end{array}$} & & & \\
\hline & $\mathbf{N}$ & $\%$ & $\mathbf{N}$ & $\%$ & $\mathbf{N}$ & $\%$ & \\
\hline Normal & 12 & 28,6 & 30 & 71,4 & 42 & 53,1 & 0,089 \\
\hline
\end{tabular}




\begin{tabular}{|c|c|c|c|c|c|c|c|}
\hline \multirow{3}{*}{$\begin{array}{l}\text { Perkem } \\
\text { bangan } \\
\text { Emosional }\end{array}$} & \multicolumn{4}{|c|}{ Perilaku Menyimpang } & \multirow{2}{*}{\multicolumn{2}{|c|}{ Total }} & \multirow{3}{*}{$\begin{array}{l}\mathbf{P} \\
\text { Value }\end{array}$} \\
\hline & \multicolumn{2}{|c|}{ Ada } & \multicolumn{2}{|c|}{$\begin{array}{l}\text { Tidak } \\
\text { Ada }\end{array}$} & & & \\
\hline & $\mathbf{N}$ & $\%$ & $\mathbf{N}$ & $\%$ & $\mathbf{N}$ & $\%$ & \\
\hline Borderline & 4 & 14,8 & 23 & 85,2 & 27 & 34,1 & \\
\hline Abnormal & 0 & 0 & 10 & 100 & 10 & 12,6 & \\
\hline Jumlah & 16 & 20,3 & 63 & 79,7 & 79 & 100 & \\
\hline
\end{tabular}

Hasil uji statistik didapatkan nilai Person Chi-Square 0,089 dengan pvalue lebih besar dari 0,05 , artinya tidak terdapat hubungan antara perkembangan emosional terhadap perilaku menyimpang di SMP Bukit Raya Pekanbaru tahun 2015.

Hasil penelitian menunjukkan bahwa sesuai dengan analisis data dengan ChiSquarememberikan hasil $\mathrm{p}=0,089$, oleh karena nilai $\mathrm{p}>0,05$ maka dalam penelitian ini tidak terdapat hubungan antara perkembangan emosional terhadap perilaku menyimpang pada usia remaja SMP Bukit Raya Pekanbaru tahun 2015.

Emosi remaja yang lebih cenderung kuat dibandingkan dengan daya fikir remaja, tentu saja akan berpengaruh terhadap perkembangan emosional yang dimiliki oleh tiap responden. Selain itu, kematangan tiap emosi tiap individu yang berbeda-beda juga berpengaruh, hal ini didukung oleh Ali dan Asrori (2008) berpendapat bahwa kematangan emosi remaja dipengaruhi oleh lingkungan, pengalaman dan kebudayaan masing- masing individu.

Tingkat perilaku menyimpang dari hasil penelitian perkembangan emosional dari hasil penelitian dalam tingkat normal sebanyak 42 responden $(53,16 \%)$, sedangkan perilaku menyimpang dari hasil ini adalah tidak ada melakukan sebanyak 63 responden $(79,74 \%)$,

Hasil penelitian pada remaja SMP Bukit Raya menunjukkan bahwa tidak terdapat hubungan antara perkembangan emosional dan perilaku menyimpang, hal ini disebabkan karena lingkungan sekolah yang mengarah kearah hal yang lebih positif seperti pengembangan diri, kegiatan ekstrakulikuler dan intrakulikuler, serta sarana dan prasarana yang memadai. Santrock (2007) faktor-faktor yang mempengaruhi perilaku remaja adalah faktor lingkungan dan salah satunya lingkungan sekolah. Lingkungan sekolah yang baik akan membuat perilaku remaja menjadi baik begitu juga sebaliknya.

Tingkat emosional yang normal juga mampu mencegah remaja melakukan perilaku menyimpang. Dalam hal ini remaja mampu dalam memahami, mengelola serta mengendalikan emosinya karena pengaruh proses perkembangan, sehingga remaja mampu melakukan perilaku kearah yang positif.

\section{KESIMPULAN DAN SARAN}

Hasil penelitian menunjukkan bahwa tidak adanya hubungan yang bermakna antara perkembangan emosional terhadap perilaku menyimpang pada remaja di SMP Bukit Raya Pekanbaru. Disarankan kepada pihak sekolah agar lebih meninhgkatkan lagi program-program ekstrakulikuler dan intrakulikuler dan perkembangan diri bagi peserta didik.

\section{DAFTAR PUSTAKA}

Ali, Muhammad., Asrori, Muhammad. 2012. Psikologi Remaja. Jakarta: Bumi Aksara

Baihaqi, Sunardi., N. Rinaldi, Riksma., Heryanti, Euis. 2007. Psikiatri. Bandung: Refika Aditama.

Hidayat, Aziz Alimut. 2007. Metode Penelitian Kebidanan Teknik Analisa Data. Jakarta: Salemba Medika

Hidayat, Aziz Alimut. 2010. Metode Penelitian Kebidanan Teknik Analisa Data. Jakarta: Salemba Medika

Hartanto. 2010. Kuesioner Kekuatandan Kesulitan: The Strength andDifficulties Questionare(SDQ)Workshop CPD III. Semarang: IDAI

http://Noviana Ayu Pratiwi 11.web.unair.ac.id: diunduh pada tanggal 02 februari 2015

Nasir, Abdul., Muhith, Abdul. 2010. Dasar dasar Keperawatan Jiwa. Bandung: Salemba Medika.

Notoatmodjo, Soekidjo. 2012. Metodologi Penelitian Kesehatan. Jakarta: Rinka Cipta

Nurhisam, Juntika., Agustin, Mubiar. 2011. Dinamika Perkembangan Anak Dan Remaja. Bandung: Refrika Aditama 
Rasmun. 2009. Keperawatan Kesehatan Mental Psikiatri Terintegritasi Dengan Keluarga. Jakarta: Sagung Seto.

Santrock, John. 2007. Perkembangan Anak. Jakarta: Erlangga

Saryono, Setiawan, Ari. 2010. Metode Penelitian. Yogyakarta: Nuha Medika

Sokolova, Irina V, dkk.2014. Keperibadian Anak. Yogyakarta: Katahati.
Suherman. 2000. Perkembangan Anak. Yogyakarta: Graha Ilmu.

Tarwoto. 2010. Kesehatan Remaja. Jakarta: Salemba Medika

www.bps.go.id; diunduh 7 februari 2015

Zulkifli.2009. Psikologi Perkembangan Psikologi. Bandung: Rosda Karya

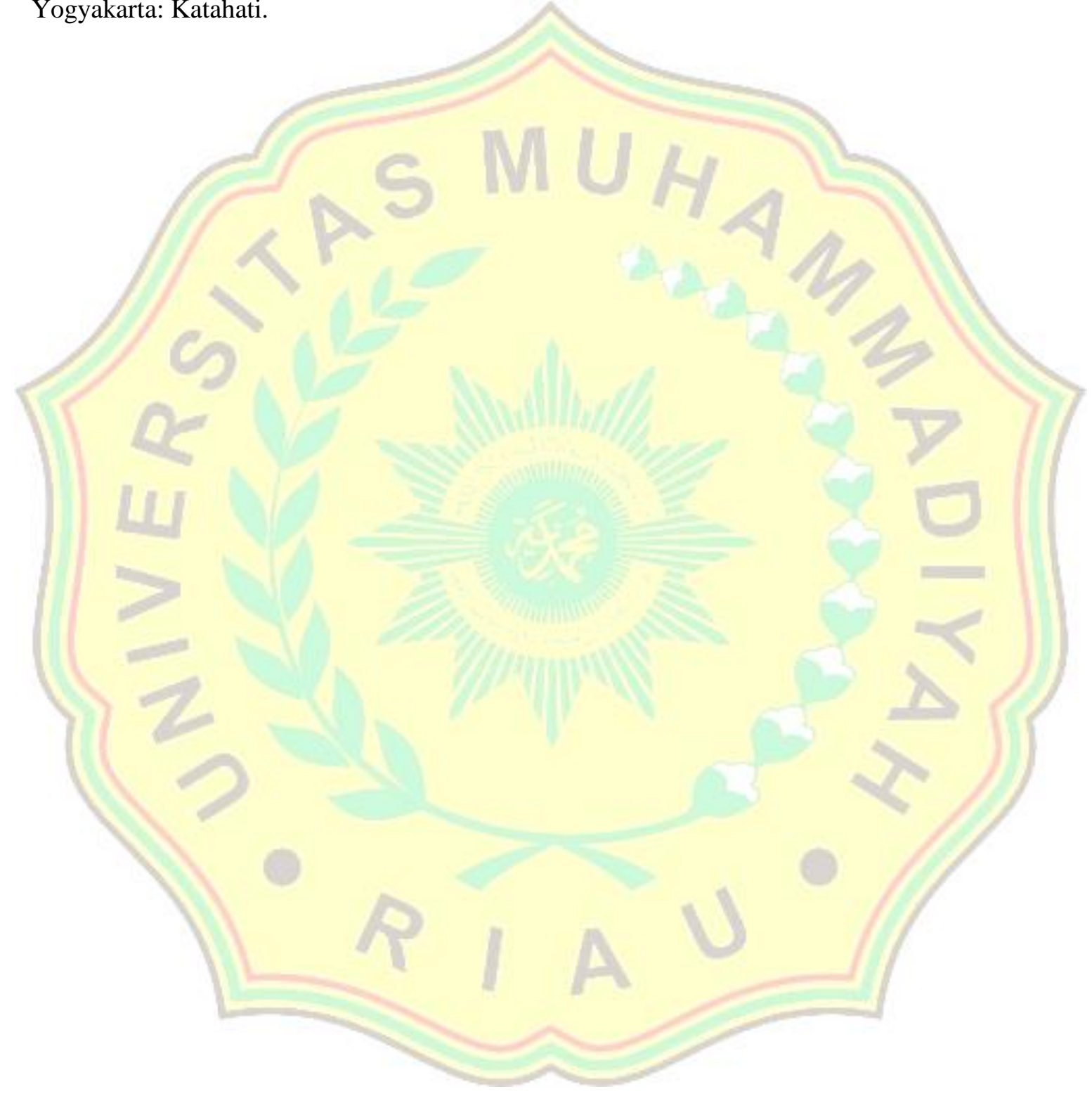

